\title{
The prolactin receptor mediates HOXA1-stimulated oncogenicity in mammary carcinoma cells
}

\author{
LIN HOU ${ }^{1,4}$, BING XU $^{1}$, KUMARASAMYPET M. MOHANKUMAR ${ }^{1,5}$, VINCENT GOFFIN $^{2}$, \\ JO K. PERRY ${ }^{1}$, PETER E. LOBIE ${ }^{1,3}$ and DONG-XU LIU ${ }^{1}$ \\ ${ }^{1}$ Liggins Institute, University of Auckland, Auckland 1023, New Zealand; ${ }^{2}$ INSERM, Unit 845, Research Center \\ in Growth and Signaling, University Paris Descartes, Sorbonne Paris Cité, Faculté de Médecine Necker, \\ Paris 75015, France; ${ }^{3}$ Cancer Sciences Institute of Singapore and Department of Pharmacology, \\ National University of Singapore, Singapore 117456, Republic of Singapore
}

Received August 29, 2012; Accepted September 24, 2012

DOI: $10.3892 /$ ijo.2012.1660

\begin{abstract}
The HOX genes are a highly conserved subgroup of homeodomain-containing transcription factors that are crucial to normal development. Forced expression of HOXA1 results in oncogenic transformation of immortalized human mammary cells with aggressive tumour formation in vivo. Microarray analysis identified that the prolactin receptor (PRLR) was significantly upregulated by forced expression of HOXA1 in mammary carcinoma cells. To determine prolactin (PRL) involvement in HOXA1-induced oncogenicity in mammary carcinoma cells (MCF-7), we examined the effect of human prolactin (hPRL)-initiated PRLR signal transduction on changes in cellular behaviour mediated by HOXA1. Forced expression of HOXA1 in MCF-7 cells increased PRLR mRNA and protein expression. Forced expression of HOXA1 also enhanced hPRL-stimulated phosphorylation of both STAT5A/B and $\mathrm{p} 44 / 42$ MAPK, and increased subsequent transcriptional activity of STAT5A and STAT5B, and Elk-1 and Sapla, respectively. Moreover, forced expression of HOXA1 in MCF-7 cells enhanced the hPRL-stimulated increase in total cell number as a consequence of enhanced cell proliferation and cell survival, and also enhanced hPRL-stimulated anchorage-independent growth in soft agar. Increased anchorage-independent growth was attenuated by the PRLR antagonist $\Delta 1-9-G 129 R-h P R L$. In conclusion, we have demonstrated that HOXA1 increases
\end{abstract}

Correspondence to: Dr Dong-Xu Liu, Liggins Institute, University of Auckland, 85 Park Road, Grafton, Private Bag 92019, Auckland 1023, New Zealand

E-mail: dx.liu@auckland.ac.nz

Present address: ${ }^{4}$ Molecular Medicine and Pathology, School of Medical Sciences, Faculty of Medical and Health Sciences, University of Auckland, Private Bag 92019, Auckland 1023, New Zealand; ${ }^{5}$ St. Jude Children's Research Hospital, Memphis, TN 38105, USA

Key words: prolactin receptor, HOXA1, mammary carcinoma, oncogenicity, mammary carcinoma cells expression of the cell surface receptor PRLR and enhances PRLR-mediated signal transduction. Thus, the PRLR is one mediator of HOXA1-stimulated oncogenicity in mammary carcinoma cells.

\section{Introduction}

The HOX genes are a highly conserved subgroup of the homeobox superfamily consisting of four groups (A, B, C and D) clustered in four chromosomal loci. Mammalian genomes have 39 HOX genes, which are thought to have arisen from a series of gene duplication events occurring during evolution (1). HOX genes are crucial in normal development and regulate numerous biological processes such as apoptosis, receptor signalling, differentiation, motility and angiogenesis (2). HOX genes are also well established as having oncogenic potential in cancer. Altered expression of HOX genes are linked to both oncogenesis and tumour suppression depending on the context $(1,2)$. For example, aberrations in HOX gene expression have been observed in a variety of cancers such as melanoma (3), myeloma (4), renal (5), lung (6), pancreatic (7), ovarian (8), prostate (9) and breast cancers (10-14). In breast cancer, some HOX genes are overexpressed whereas others are underexpressed and mutations are rarely observed (2). However, the exact function of HOX genes in cancer is not well understood $(1,2)$.

HOXA1 is expressed very transiently during the early stages of embryonic development (15). It is also expressed in a variety of adult tissues (16). Increased expression of murine HOXA1 has been observed in neoplastic mammary glands (11) and ectopic expression of HOXA1 in transfected rodent cells induces tumorigenesis (17). HOXA1 mRNA is detected in the human mammary carcinoma cell line, MCF-7, in response to retinoic acid and progestin treatment, as well as in breast cancer tissues $(16,18)$, indicating a potential role for HOXA1 in cellular transformation and breast cancer progression. Indeed, our group has demonstrated that HOXA1 is a human mammary epithelial oncogene, and that forced expression of HOXA1 in immortalized human mammary epithelial MCF-10A cells resulted in oncogenic transformation and aggressive tumour formation in vivo (10). Microarray analysis identified that HOXA1-stimulated 
oncogenicity in human mammary carcinoma cells was mediated by selective upregulation of components of the p44/42 MAP kinase pathway (19). However, the molecular mechanisms by which HOXA1 induces oncogenic transformation and promotes tumorigenicity remain largely unclear.

The involvement of both prolactin (PRL) and the PRL receptor (PRLR) in breast cancer has recently received increased attention $(20,21)$. PRL is not just synthesized in the pituitary, but is also expressed in many extrapituitary sites, including the mammary gland, where it acts as an autocrine/paracrine factor (22). For example, PRL is produced in both the stromal and epithelial compartments of normal breast tissue (23). In addition, $80 \%$ of breast tumours stain positive for PRLR (24). Breast tumours also express higher levels of the PRLR than adjacent healthy tissue $(25,26)$. A recent study observed increased PRLR expression in an aggressive form of lobular carcinoma (27). Moreover, a constitutively active genetic variant of the PRLR has been recently identified in patients presenting with breast tumours (28), suggesting that sustained prolactin signalling may participate in breast tumorigenesis.

It is generally believed that the PRL signalling cascade is initiated upon binding of PRL to the PRLR with one receptor binding to a high affinity site 1 on the PRL molecule, and a second receptor binding to a lower affinity site 2 , forming an active complex composed of one hormone molecule and a receptor homodimer (20); although a ligand-independent predimerization of the PRLR model is also proposed where the binding of ligand to the preformed dimer initiates conformational changes leading to activation of the receptor (29). The active ligand/receptor binding results in allosteric reorganization which brings JAK2 kinase into close proximity to the intracellular domain of the receptor, enabling its phosphorylation (30). The phosphorylated Janus kinase 2 (JAK2) recruits several kinases and adaptor proteins which activate downstream signalling pathways such as signal transducer and activator of transcription 5A/B (STAT5A/B), MAPK and PI3K (31). The JAK2/STAT5 pathway is one of the predominant pathways activated by PRLR to mediate transcriptional activation $(30,32,33)$. PRL-stimulated JAK2 activation results in the tyrosine phosphorylation of STAT5 and subsequent translocation of this protein into the nucleus, promoting transcription of numerous genes, for example, cytokine inducible $\mathrm{SH} 2$-containing protein, $\beta$-casein, c-Myc and cyclin D1 $(31,34,35)$.

In the present study, we demonstrate that forced expression of HOXA1 in the mammary carcinoma cell line MCF-7, increases both PRLR mRNA and protein expression. As a result, HOXA1 enhances PRL-stimulated and PRLR-mediated activation of STAT5A/B and MAPK downstream signal transduction pathways and consequent cell proliferation and survival. HOXA1 also enhances PRL-stimulated anchorage-independent growth, which is partially inhibited by the PRLR antagonist $\Delta 1-9-G 129 R-h P R L$.

\section{Materials and methods}

Cell culture. The human mammary carcinoma cell line MCF-7, was obtained from the American Type Culture Collection and cultured in RPMI-1640 medium supplemented with $10 \%$ heatinactivated fetal bovine serum (FBS), $100 \mathrm{IU} / \mathrm{ml}$ penicillin,
$100 \mu \mathrm{g} / \mathrm{ml}$ streptomycin and $2 \mathrm{mM}$ L-glutamine in a humidified incubator with $5 \% \mathrm{CO}_{2}$ at $37^{\circ} \mathrm{C}$. Stable forced expression of HOXA1 in MCF-7 cells (MCF7-HOXA1) and its control cell line (MCF7-VECTOR); and stable depletion of endogenous HOXA1 in MCF-7 cells using siRNA (MCF7-siHOXA1) and its control cell line (MCF7-siControl) have been described previously (19). Briefly, MCF7-HOXA1 and MCF7-VECTOR were established by stably transfecting MCF-7 cells with a HOXA1 expression plasmid (pCMV Tag2B-HOXA1) and the empty vector (pCMV Tag2B), respectively; MCF7-siHOXA1 and MCF7-siControl were established by stably transfecting MCF-7 cells with the HOXA1 siRNA expression plasmid (pSilencer-HOXA1) (36) and the negative control siRNA vector (pSilencer 2.1-U6 hygro) (Applied Biosystems/Ambion, Austin, TX), respectively.

Preparation of total-RNA and RT-PCR analysis. Total-RNA isolation using TRIzol reagent (Invitrogen, Carlsbad, CA) and RT-PCR using one-step RT-PCR kit (Qiagen GmbH, Hilden, Germany) were performed as previously described (37). All RNA samples were treated with DNase I using a RNase-free DNase kit (Qiagen $\mathrm{GmbH}$ ) to avoid genomic DNA contamination. In order to compare the PCR products semi-quantitatively, 20-40 cycles of PCR were carried out to determine the linearity of the PCR amplification. Amplification occurring in the linear range was utilized for quantification. $\beta$-actin amplification served as an internal control. The sequences of the oligonucleotide primers used for the RT-PCR were as follows: sense 5'-CCAACTTCACTACCAAGCAGC-3' and antisense 5'-GACT TCTCTGAGGATTCCTCG-3' for HOXA1 (19); sense 5'-AATG TTCAGCGAATTCGATAAACG-3' and antisense 5'-CTTTGG TTTCAGGATGAACCTGG-3' for PRL, which amplify a 323 bp fragment spanning the exons 2-5 of the gene; sense 5'-GGACCCCCAGTGCATAAGCAT-3' and antisense 5'-CTCTTCTCTAGACTTAATGGTTTGA-3' for PRLR long form (PRLR-LF); sense 5'-AGAACACCCAAGTCAAGGT GAC-3' and antisense 5'-TGAATTCTGGTATATGCTCTTC AG-3' for PRLR short form S1a; sense 5'-ATGCTCATCTGTT GGAGGTGAC-3' and antisense 5'-GGGTGCACAGTCTGT CCTGTG-3' for PRLR short form S1b; sense 5'-ATGATATCG CCGCGCTCG-3' and antisense 5'-CGCTCGGTGAGGA TCTTCA-3' for $\beta$-actin (19). Amplified PCR products were visualized under UV light on a $1.5 \%$ agarose gel stained with ethidium bromide.

Transient transfection and luciferase reporter assay. Cells were plated in 6-well plates the day before transfection so they reached $60-80 \%$ confluence upon transfection. The indicated reporter plasmids ( $0.5 \mu \mathrm{g}$ per well), and $\beta$-galactosidase reporter vector $(0.2 \mu \mathrm{g}$ per well $)$ to control for transfection efficiency, were cotransfected using SAINT MIX according to the manufacturer's instructions (Synvolux Therapeutics BV, Groningen, The Netherlands). Cells were transfected in serum-free RPMI medium for $4 \mathrm{~h}$, then the medium was changed to fresh serumfree RPMI with or without $2 \mu \mathrm{g} / \mathrm{ml}$ of recombinant human PRL (hPRL) (38). Luciferase and $\beta$-galactosidase activity was quantified $24 \mathrm{~h}$ later using the Beta-Glo Assay System following the manufacturer's instructions (Promega, Madison, WI) essentially as previously described (39). Luciferase activity values were normalized to $\beta$-galactosidase activity. At least three independent experiments, each in triplicate, were carried out. 
STAT5 reporter assay. STAT5-dependent transcription was measured using a reporter gene plasmid pSPI-LUC (a kind gift from Dr Haldosen, Karolinska, Sweden). pSPI-LUC contains six tandem repeat copies of the $\gamma$-interferon-activated sequence (GAS)-like element of the serine protease inhibitor (SPI) 2.1 gene promoter fused to a minimal kinase $(\mathrm{TK})$ promoter $(-104$ to +51$)$ and cloned into the pGL2 basic luciferase vector (Promega) $(40,41)$.

ERK reporter assay. ERK1/2 (p44/42)-dependent transcription was measured by using an ERK luciferase reporter plasmid (42). It contains an Egr-1 promoter fragment comprising of $624 \mathrm{bp} \mathrm{5'}$ of the initiation codon cloned into the pGLBasic luciferase vector (Promega). This promoter region contains five $\mathrm{SRF} /$ Ets response elements, which are responsive to p44/42 MAPK stimulation through phosphorylation of Elk-1 and Sapla $(43,44)$, but has no STAT5 response elements (42).

Western blot analysis. Cells were cultured as described above. In some experiments, cells were treated just before harvest with $2 \mu \mathrm{g} / \mathrm{ml}$ of hPRL for $15 \mathrm{~min}$ after serum deprivation in serum-free medium for $24 \mathrm{~h}$. Whole cell lysates were then prepared according to protocols described previously (40). Western blot analysis was essentially performed as previously described (45) using the following antibodies: anti-PRLR monoclonal antibody U5 (Abcam, Cambridge, UK); antiphospho-STAT5A/B antibody (Millipore, Billerica, MA); anti-Stat5 and anti-p44/42 MAPK antibodies (Santa Cruz Biotechnology, Santa Cruz, CA); anti-phospho-p44/42 MAPK antibody (Cell Signaling Technology, Beverly, MA); anti- $\beta$-actin antibody (Sigma-Aldrich, St. Louis, MO). Immunolabelling was visualized by SuperSignal ${ }^{\circledR}$ West Dura Extended Duration Substrate kit (Pierce Biotechnology, Rockford, IL) according to the manufacturer's instructions.

Total cell number assay. Cells were seeded in 6-well plates at a density of $5 \times 10^{4}$ cells per well, in triplicate, in $3 \mathrm{ml}$ of complete RPMI medium containing $10 \%$ FBS or serum-free medium, with or without of $2 \mu \mathrm{g} / \mathrm{ml}$ of hPRL for 3 days. The total cell number in each well was quantified with a haemocytometer.

5'-Bromo-2'-deoxyuridine incorporation assay. S-phase entry was measured by 5'-bromo-2'-deoxyuridine (BrdU) incorporation as previously described (46). In brief, cells were cultured in full media overnight, and then in serum-free media with or without $2-\mu \mathrm{g} / \mathrm{ml}$ of hPRL for $24 \mathrm{~h}$. Subconfluent cells were pulse labelled with BrdU at a concentration of $20 \mu \mathrm{M}$ in serum-free media for $30 \mathrm{~min}$. Cells were washed twice with PBS and then fixed in 4\% paraformaldehyde in PBS (pH 7.4) for $30 \mathrm{~min}$. To denature DNA, cells were treated with $2 \mathrm{~N} \mathrm{HCl}$ for $1 \mathrm{~h}$ at room temperature with gentle shaking. The detection of incorporated BrdU was performed using a Vectastain Elite ${ }^{\circledR}$ ABC kit (Vector Laboratories, Burlingame, CA) according to the manufacturer's instructions. Cells were documented by photomicroscopy. Cells in random microscopic fields were analyzed to determine the percentage of cells with nuclear BrdU incorporation relative to the total number of cell nuclei. Over 1,200 cells from each treatment were analysed. The experiments were carried out in triplicate, and repeated at least three times.
Measurement of apoptosis. Apoptotic cell death was measured by fluorescent microscopic analysis of cell DNA staining patterns using Hoechst 33258 as previously described (46). In brief, cells ( $2 \times 10^{5}$ cells per well) were seeded on glass coverslips in 6 -well plates in complete growth media for $24 \mathrm{~h}$, then incubated in serum-free media with or without $2 \mu \mathrm{g} / \mathrm{ml}$ of hPRL for an additional $24 \mathrm{~h}$. The cells were then fixed in $4 \%$ paraformaldehyde in PBS ( $\mathrm{pH} 7.4$ ) for $15 \mathrm{~min}$, permeabilized with $0.6 \%$ Tween- $20^{\circledR}$, and stained with the karyophilic dye Hoechst $33258(8 \mu \mathrm{g} / \mathrm{ml})$ for $30 \mathrm{~min}$ at room temperature in the dark. Cells were then washed with PBS and nuclear morphology was examined under a UV-visible fluorescence microscope. Cells with apoptotic nuclear characteristics such as nuclear condensation and fragmentation were scored as apoptotic. For statistical analysis, over 400 cells of each treatment were examined in eight random microscopic fields at x400 magnification. The experiments were carried out in triplicate, and repeated at least three times.

Colony formation in soft agar. For the soft agar colony formation assay, $5 \times 10^{4}$ cells were cultured in 6-well plates in $0.35 \%$ agar in RPMI media containing 5 or $10 \%$ FBS, with or without $2 \mu \mathrm{g} / \mathrm{ml}$ of hPRL. RPMI media ( $2 \mathrm{ml}$ ) containing 5 or $10 \% \mathrm{FBS}$, with or without $2 \mu \mathrm{g} / \mathrm{ml}$ of hPRL was added to the wells. The plates were incubated at $37^{\circ} \mathrm{C}$ in a humidified incubator for 14 days and the media was replaced every day. Cells were stained with $0.5 \mathrm{ml}$ of $0.005 \%$ crystal violet in distilled water for $1 \mathrm{~h}$ and destained for $2 \mathrm{~h}$ in water. Colonies were inspected and photographed (47). To determine the role of HOXA1-mediated PRLR expression on anchorage-independent growth, medium containing $10 \%$ FBS with or without $10 \mu \mathrm{g} / \mathrm{ml}$ of the PRLR antagonist, $\Delta 1-9-G 129 R-h P R L$ was added to the wells instead $(38,48)$. The experiments were carried out in triplicate, and repeated at least three times.

Statistical analysis. All experiments were repeated at least three times. All numerical data are expressed as mean $\pm \mathrm{SE}$ (standard error of the mean) from a representative experiment performed in triplicate, and statistical analyses were done by Student's t-test using Microsoft Excel XP.

\section{Results}

PRL and PRLR are expressed in human mammary carcinoma MCF-7 cells. MCF-7 cells were reported to express PRL mRNA (49-52) and thus exhibit low levels of PRL protein expression $(0.3 \pm 0.08 \mathrm{ng} / \mathrm{ml} /$ day in conditioned medium) (52). As shown in Fig. 1A, a pair of PRL specific primers for the detection of PRL mRNA expression spanning the exons 2-5 of the gene produced a single fragment in MCF-7 total-RNA by RT-PCR. The size of the band is the predicted size of $323 \mathrm{bp}$ appropriate for PRL mRNA and sequence was confirmed by DNA sequencing.

PRL mediates its activities via the PRLR, which has many variants derived from alternative splicing. The PRLR-LF confers the entire repertoire of PRL-induced signalling whereas the short and intermediate isoforms either mediate a partial response to PRL or inhibit PRL dependent signalling (31). In breast cancer, the PRLR-LF was predominantly expressed and was found to be stimulatory while the two short forms, S1a and S1b, were found to be inhibitory of the activa- 
A RT-PCR

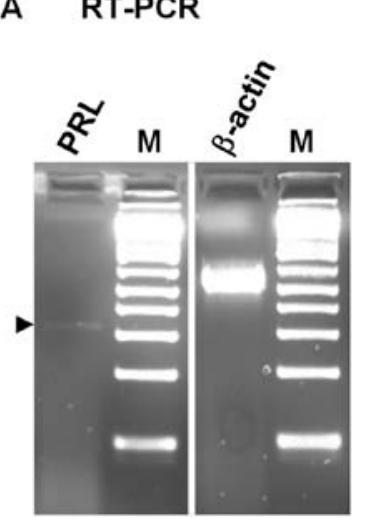

B RT-PCR

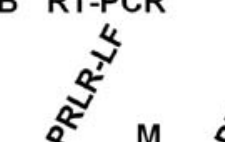

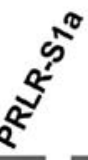
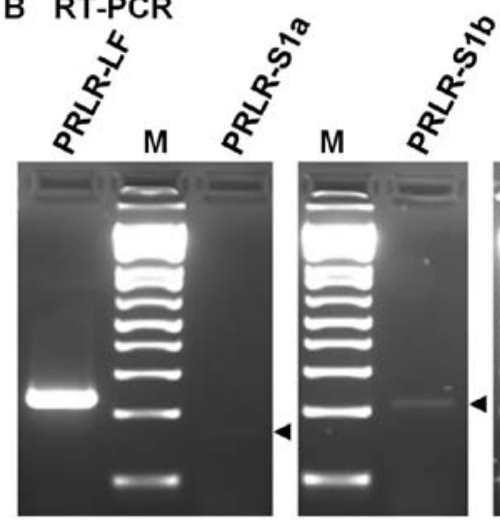

E Western
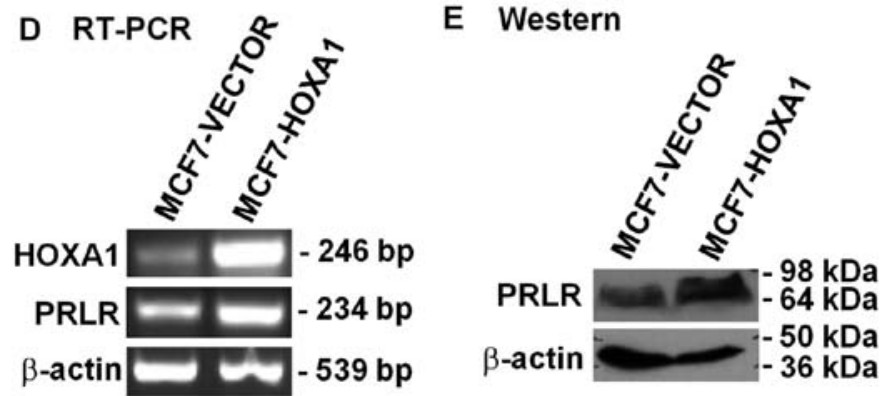

Figure 1. Forced expression of HOXA1 increased prolactin receptor long form (PRLR-LF) expression in mammary carcinoma cells. (A) RT-PCR. Total-RNA was isolated from mammary carcinoma MCF-7 cells and the PRL mRNA (323 bp) expression was determined by a pair of primers spanning the exons 2-5 of the gene using a one-step RT-PCR kit (Qiagen). $\beta$-actin mRNA (539 bp) was used as the relative expression control. (B) The expression of PRLR isoforms: PRLR-LF (224 bp), PRLR-S1a (165 bp) and PRLR-S1b (216 bp) in MCF-7 cells was determined by RT-PCR. $\beta$-actin mRNA was included as the relative expression control. (C) Western blot detection of PRLR in MCF-7 cells by use of the anti-PRLR monoclonal antibody U5 (Abcam). An immunoreactive protein of $\sim 90 \mathrm{kDa}$ was clearly observed. The sizes of molecular weight of protein markers in kDa are shown on the right. (D) RT-PCR. Stable forced expression of HOXA1 in the mammary carcinoma cell line, MCF-7 (MCF7-HOXA1) and its control cell line (MCF7-VECTOR) were established as previously described (19). The mRNA levels of HOXA1, PRLR and $\beta$-actin in these stables were detected by RT-PCR. The sizes of amplified products are shown on the right. (E) PRLR protein expression in MCF7-HOXA1 and MCF7-VECTOR stables cells was determined by western blot analysis using the anti-PRLR monoclonal antibody U5 (Abcam). $\beta$-actin was used as loading control for cell lysates. The sizes of protein markers in $\mathrm{kDa}$ are shown on the right. M, $1 \mathrm{~Kb}$ Plus DNA Ladder (Invitrogen): (from the bottom) 100, $200,300,400,500$ and $650 \mathrm{bp}$. Solid arrows indicate the positions of weak bands.

tion induced by PRL through the PRLR-LF (53). Therefore, the expression of these isoforms in MCF-7 cells was first analyzed by RT-PCR. As shown in Fig. 1B, the PRLR-LF transcript was the predominant variant and the short forms Sla and S1b were much less abundant in MCF-7 cells. The expression of PRLR protein was examined by western blot analysis using the anti-PRLR monoclonal antibody U5 (54). Consistent with RT-PCR results, a single protein band of $\sim 90 \mathrm{kDa}$ equivalent to the PRLR-LF isoform was detected in MCF-7 cells (Fig. 1C), indicating the expression of the short isoforms was very low and undetectable.

Forced expression of HOXAl increased PRLR-LF expression in mammary carcinoma cells. We have previously demonstrated that expression of HOXA1 results in oncogenic transformation of immortalized human mammary epithelial cells MCF-10A with tumour formation in vivo (10). Subsequently we identified molecules that could potentially be involved in HOXA1-mediated oncogenic transformation in a cDNA microarray study using two complementary pairs of cell lines, forced expression or depleted expression of HOXA1 in human mammary carcinoma MCF-7 cells (19). PRLR was one of the genes identified in this study that was upregulated in response to forced expression of HOXA1 and accordingly downregulated in response to depletion of HOXA1 in the microarray analysis (19). To verify that HOXA1 regulates PRLR, we examined the expression of PRLR-LF mRNA in the stable human mammary carcinoma MCF-7 cells with forced HOXA1 overexpression by semi-quantitative RT-PCR. As demonstrated in Fig. 1D, HOXA1-overexpressing MCF7-HOXA1 cells expressed much higher levels of PRLR-LF mRNA than the control cell line, MCF7-VECTOR. Concordantly, HOXA1-depleted MCF7-siHOXA1 cells expressed less PRLR-LF mRNA than the control MCF7-siControl cells (data not shown). HOXA1 overexpression or depletion did not significantly affect the expression of the Sla and S1b isoforms in these stable cells. To determine whether HOXA1 stimulated PRLR-LF expression manifested at the protein level, western blot analysis was used to examine the expression of PRLR protein in the stably transfected cell lines. Forced expression of HOXA1 in MCF7-HOXA1 cells increased PRLR-LF protein expression compared with the MCF7-VECTOR cell line (Fig. 1E), while depletion of HOXA1 in MCF7-siHOXA1 cells decrease PRLR-LF protein expression compared with the control MCF7-siControl cell line (data not shown). Thus, HOXA1 specifically increased the expression of PRLR-LF mRNA and protein in MCF-7 cells. 
A

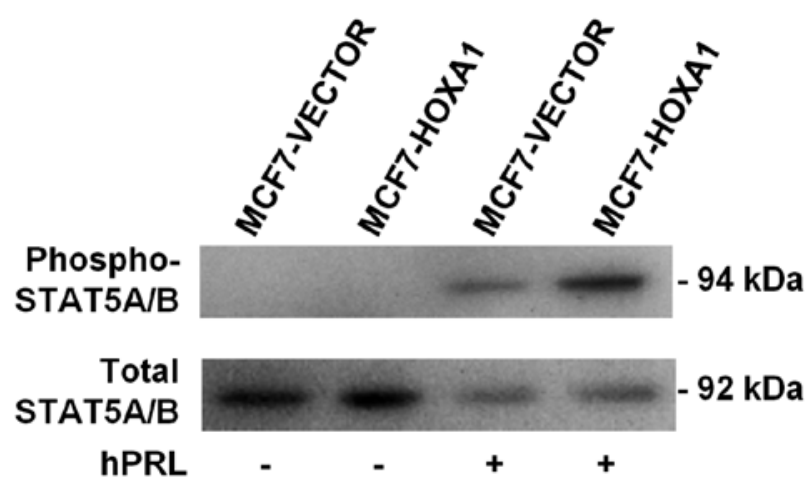

B

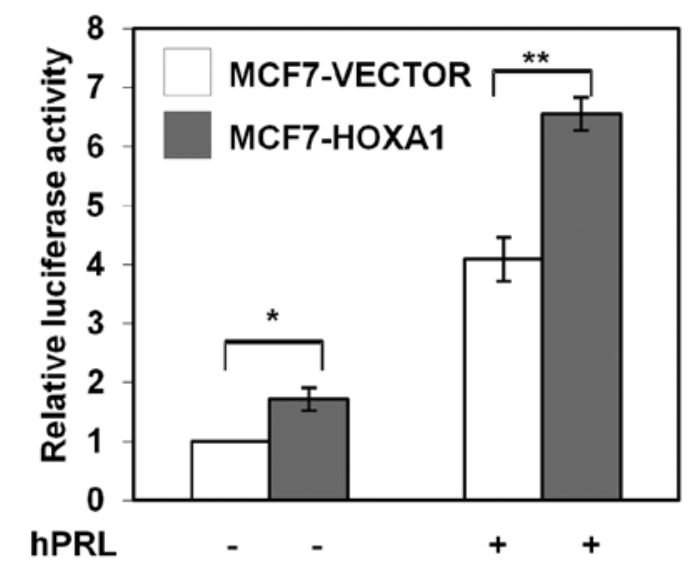

Fold increase by hPRL: $\quad 4.1 \quad 3.8$

Figure 2. Forced expression of HOXA1 enhanced PRL-stimulated STAT5 activation in human mammary carcinoma cells. (A) Western blot analyses. Cells were serum deprived in serum free media for $24 \mathrm{~h}$, followed by $15-\mathrm{min}$ stimulation with $2 \mu \mathrm{g} / \mathrm{ml}$ of hPRL. Soluble whole cellular extracts were run on a $12.5 \%$ SDS-PAGE and immunoblotted using an anti-phospho-STAT5A/B antibody (Millipore) for tyrosine phosphorylated STAT5A/B protein and an anti-Stat5 antibody (Santa Cruz Biotechnology) for total STAT5A/B protein as a loading control for cell lysates. The sizes of detected protein bands in $\mathrm{kDa}$ are shown on the right. (B) STAT5 reporter assay. STAT5-dependent transcription was measured using a luciferase reporter gene plasmid pSPI-LUC, which contains six tandem repeat copies of the $\gamma$-interferon-activated sequence (GAS)-like element of the serine protease inhibitor (SPI) 2.1 gene promoter. MCF7-HOXA1 (solid bar) and MCF7-VECTOR (open bar) cells were co-transfected with the reporter plasmid together with a $\beta$-galactosidase reporter vector as the control for transfection efficiency in serum-free RPMI with (+) or without (-) $2 \mu \mathrm{g} / \mathrm{ml}$ of recombinant human prolactin (hPRL). After a further $24 \mathrm{~h}$, luciferase and $\beta$-galactosidase activities were quantified using a Beta-Glo kit (Promega). Luciferase activity values were normalized to $\beta$-galactosidase activity and presented as mean $\pm \mathrm{SE}$ (standard error of the mean) of three independent experiments each in triplicate and are presented relative to the mean of MCF7-VECTOR cells without hPRL treatment. The effect of hPRL treatment is shown as fold increase in comparison with the untreated control. ${ }^{\mathrm{P}}<0.05 ;{ }^{* *} \mathrm{P}<0.01$.

Forced expression of HOXAl enhanced hPRL-stimulated STAT5 activation in human mammary carcinoma cells. To investigate the interaction of PRLR and HOXA1, we first examined the effect of forced expression of HOXA1 on the ability of PRL to stimulate the tyrosine phosphorylation of STAT5A/B. As shown in Fig. 2A, no phosphorylation of STAT5A/B protein was observed without exogenous hPRL stimulation in either MCF7-VECTOR or MCF7-HOXA1 cells in serum free media, although the non-phosphorylated STAT5A/B protein was easily detected. However, after stimulation with exogenous hPRL, tyrosine phosphorylated STAT5A/B protein became detectable in both cell lines, with phosphorylation levels increased in MCF7-HOXA1 cells compared with the control cell line, MCF7-VECTOR (Fig. 2A), indicating that hPRL induced the phosphorylation of STAT5A/B and HOXA1 enhanced this effect.

After phosphorylation, STAT5 becomes activated and is able to recognize and bind to the GAS-like element in the promoter of the SPI 2.1 gene, thereby activating the transcription of specific genes (55-57). We therefore used the pSPI-LUC luciferase reporter plasmid which contains six tandem repeat copies of the GAS-like element to measure STAT5-dependent transcription. As shown in Fig. 2B, in the absence of hPRL stimulation the luciferase activity in MCF7-HOXA1 cells was 1.7 times higher than that in MCF7VECTOR cells, indicating that forced expression of HOXA1 in MCF-7 cells increased STAT5-dependent transcription. Stimulation with exogenous hPRL further increased the luciferase activity in both HOXA1-overexpressing MCF7HOXA1 and the control MCF7-VECTOR cells by 4.1 and 3.8 fold, respectively; MCF7-HOXA1 cells exhibited 1.6 fold higher luciferase activity than the control cells (Fig. 2B). Therefore, forced expression of HOXA1 enhanced hPRLstimulated STAT5 activation.

Forced expression of HOXAl enhanced hPRL-stimulated p44/42 MAP kinase activation in human mammary carcinoma cells. We previously demonstrated that HOXA1-stimulated oncogenicity was mediated by upregulation of components, such as GRB2, MAP kinase kinase (MEK1) and SDFR1, of the p44/42 MAP kinase pathway (19). Because the MAP kinase pathway is another important cascade activated by the PRLR, we examined the effect of HOXA1 on the ability of PRL to stimulate MAP kinase activation. As shown in Fig. 3A, although HOXA1 forced expression did not affect the total amount of p44/42 kinase expression without hPRL treatment, the level of dual phosphorylated p44/42 MAP kinase in MCF7-HOXA1 cells was higher than the control MCF7-VECTOR cells. This is consistent with our previously reported study (19). When treated with hPRL, the level of phosphorylated p44/42 MAP kinase in both cell lines increased further with significantly more phosphorylation observed in MCF7-HOXA1 cells (Fig. 3A). Therefore, forced expression of HOXA1 was able to enhance PRL-stimulated MAP kinase activation in human mammary carcinoma cells.

We next used the ERK reporter to confirm the effect of the increased level of phosphorylated p44/42 MAP kinases on the transcriptional activation of downstream effector molecules. The ERK luciferase reporter plasmid harbours the Egr-1 promoter region containing five SRF/Ets response elements but does not contain a STAT5 response element (42). This response element has been shown to specifically respond to p44/42 MAPK stimulation through phosphorylation of Elk-1 and Sapla $(43,44)$. As shown in Fig. 3B, in the absence of hPRL treatment, forced expression of HOXA1 in MCF-7 cells resulted in a 2.2-fold increase of ERK reporter activity; upon treatment with hPRL an elevated ERK reporter activity was observed in both MCF7-HOXA1 (by 3.8-fold) and MCF7-VECTOR (by 


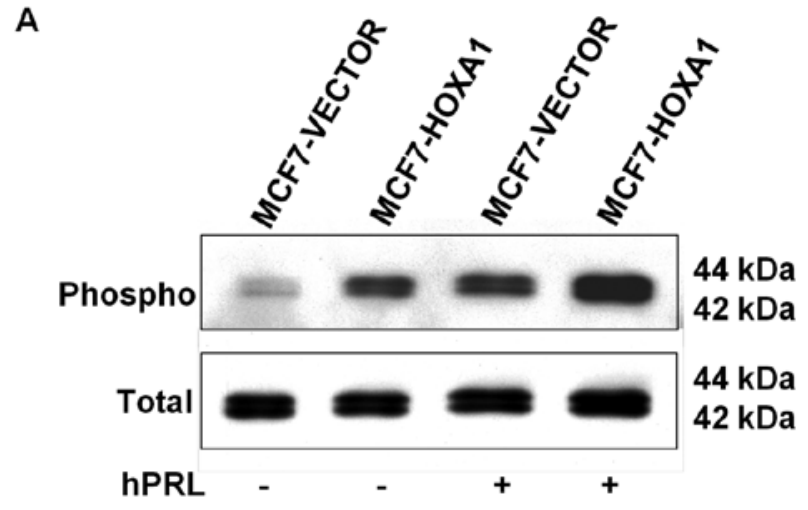

B

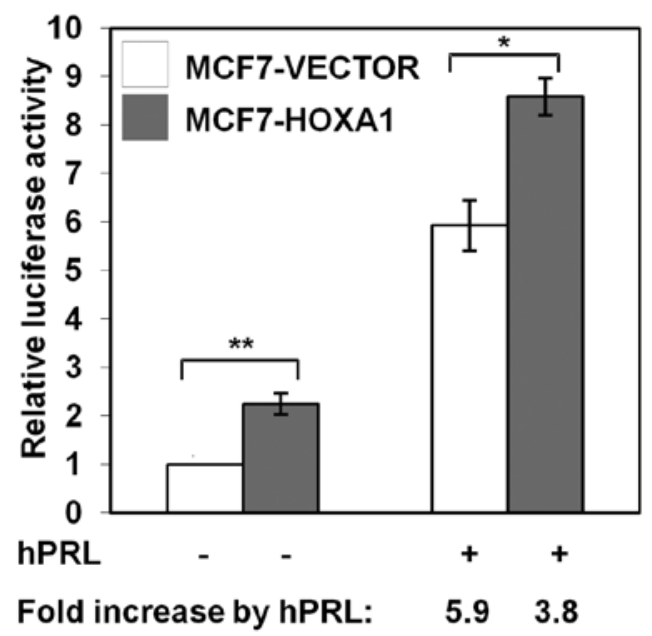

Figure 3. Forced expression of HOXA1 enhanced PRL-stimulated MAPK activation in human mammary carcinoma cells. (A) Western blot analysis. Cells were serum deprived in serum-free media for $24 \mathrm{~h}$, followed by $15 \mathrm{~min}$ stimulation with $2 \mu \mathrm{g} / \mathrm{ml}$ of hPRL. Soluble whole cellular extracts were run on a 12.5\% SDS-PAGE and immunoblotted using an anti-phospho-p44/42 MAPK antibody (Cell Signalling Technology) for phosphorylated p44/42 protein and an anti-p44/42 MAPK antibody (Santa Cruz Biotechnology) for total p44/42 protein as loading control for cell lysates. The sizes of detected protein bands in $\mathrm{kDa}$ are shown on the right. (B) ERK reporter assay. ERK1/2 (p44/42)-dependent transcription was measured by using an ERK luciferase reporter gene plasmid, which contains an egr-1 promoter fragment comprising 624 bp 5 of the initiation codon. MCF7-HOXA1 (solid bar) and MCF7-VECTOR (open bar) cells were co-transfected with the reporter plasmid together with a $\beta$-galactosidase reporter vector as the control for transfection efficiency in serum-free RPMI with (+) or without (-) $2 \mu \mathrm{g} / \mathrm{ml}$ of recombinant human prolactin (hPRL). After a further $24 \mathrm{~h}$, luciferase and $\beta$-galactosidase activities were quantified using a kit (Promega). Luciferase activity values were normalized to $\beta$-galactosidase activity and presented as mean $\pm \mathrm{SE}$ (standard error of the mean) of three independent experiments each in triplicate and are presented relative to the mean of MCF7-VECTOR cells without hPRL treatment. The effect of hPRL treatment is shown as fold increase in comparison with the untreated control. ${ }^{\mathrm{P}} \mathrm{P}<0.05 ;{ }^{* *} \mathrm{P}<0.01$.

5.9-fold) cells, with a 1.4-fold higher activity observed once again in MCF7-HOXA1 cells. Therefore, HOXA1 was able to increase PRL-stimulated transcription that was mediated via p44/42 MAPK activation in human mammary carcinoma cells.

Forced expression of HOXAl enhanced cell proliferation and survival in response to hPRL treatment in human mammary carcinoma cells. We previously demonstrated that HOXA1 stimulated an increase in MCF-7 total cell number (10), which was mediated by p44/42 MAP kinase (19). Consistent with this, the total cell number of MCF7-HOXA1 cells without hPRL treatment was significantly higher than MCF7-VECTOR cells when grown in either serum-free media or media containing 10\% FBS (Fig. 4A). After exogenous hPRL treatment, there was a significant increase in the total cell number under both serum-free and serum replete conditions in both cell types, but the cell number of MCF7-HOXA1 was significantly higher than the MCF7-VECTOR cells (Fig. 4A). HOXA1 therefore enhanced hPRL-stimulated cell growth. hPRL stimulated a greater percentage increase in cell number in HOXA1 overexpressing MCF7-HOXA1 cells (by 2.4-fold in serum-free and 1.4-fold in serum) than the control MCF7-VECTOR cells (2.0-fold in serum-free and 1.2-fold in serum) (Fig. 4A).

HOXA1-stimulated increase in total cell number in mammary carcinoma was previously shown to be the consequence of both increased cell proliferation and increased cell survival in a p44/42 MAP kinase-dependent manner $(10,19)$. We therefore examined the effect of HOXA1 on cell proliferation and survival in MCF7 cells in response to hPRL stimulation. To determine the effect of HOXA1 on hPRL stimulated cell proliferation, we analysed nuclear BrdU incorporation during entry to $\mathrm{S}$ phase. As shown in Fig. 4B, hPRL stimulated a significant increase in BrdU incorporation in both MCF7HOXA1 and MCF7-VECTOR cells. HOXA1 further enhanced the increase in S-phase entry induced by hPRL. A stronger stimulation (3.3-fold) was observed in HOXA1 expressing cells than in the vector control cells (2.2-fold) (Fig. 4B).

HOXA1 was previously demonstrated to protect mammary carcinoma cells from apoptosis induced by serum deprivation through activation of p44/42 MAP kinase-mediated signal transduction and upregulation of BCL-2 $(10,19)$. Concordantly, without hPRL treatment forced expression of HOXA1 in MCF-7 cells functioned as a potent survival stimulus and resulted in marked protection from apoptotic cell death in serum-deprived conditions. Indeed, as shown in Fig. $4 \mathrm{C}$, in the absence of hPRL forced expression of HOXA1 in MCF-7 cells reduced the rate of apoptotic cell death from $26.5 \%$ in control cells to $15.6 \%$. Treatment by hPRL reduced apoptotic cell death in both MCF7-HOXA1 (2.2-fold) and MCF7-VECTOR (1.7-fold) cells (Fig. 4C). Therefore, exogenous hPRL acts in synergy with HOXA1 to afford protection of mammary carcinoma cells against apoptotic cell death.

Forced expression of HOXAl increased hPRL-induced oncogenicity via PRLR signalling in human mammary carcinoma cells. Anchorage-independent growth is a hallmark of malignant tumour cells and a characteristic of oncogenically transformed cells (58). Forced expression of HOXA1 in mammary carcinoma cells was previously shown to significantly increase anchorage-independent growth as measured in a soft agar colony formation assay (19). In the absence of hPRL treatment forced expression of HOXA1 in MCF-7 cells significantly increased anchorage-independent growth in soft agar in media containing 5 or $10 \%$ FBS, whereas treatment with hPRL significantly increased the number of colonies formed in soft agar in both MCF7-VECTOR and MCF7-HOXA1 cells (Fig. 5A). In media with 10\% FBS, hPRL stimulated an approximate 2.2 and 1.9 -fold increase in colony numbers for both MCF7-VECTOR and MCF7-HOXA1 cells, respectively. 
A

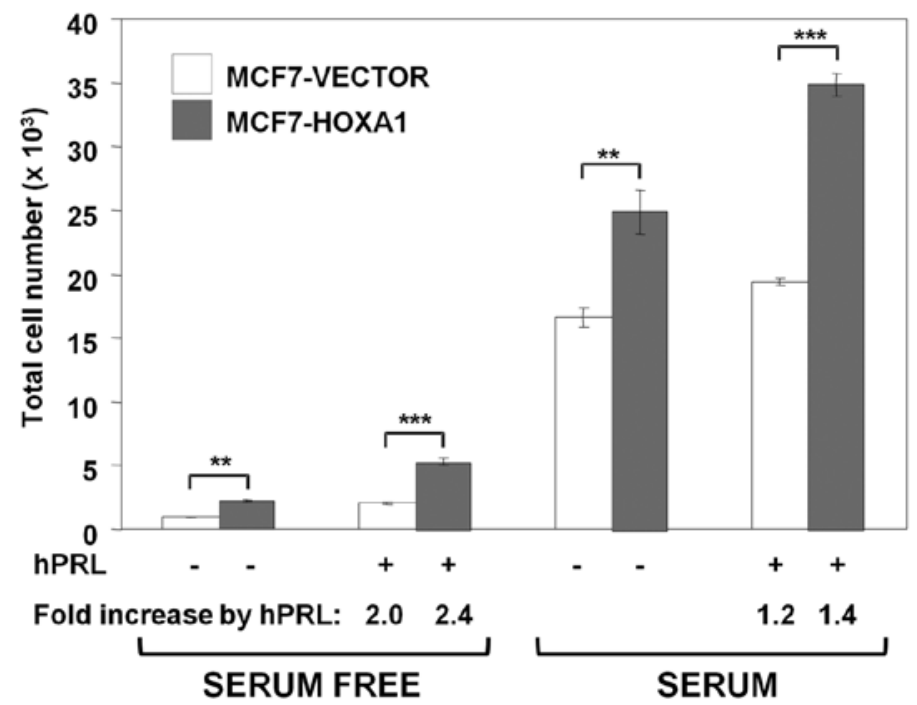

B

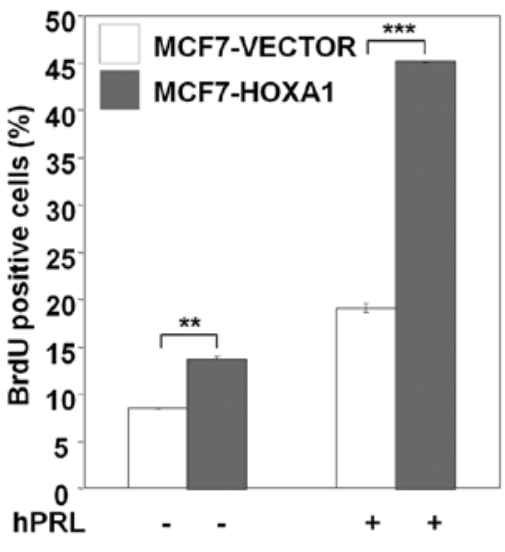

Fold increase by hPRL: $\quad 2.2 \quad 3.3$
C

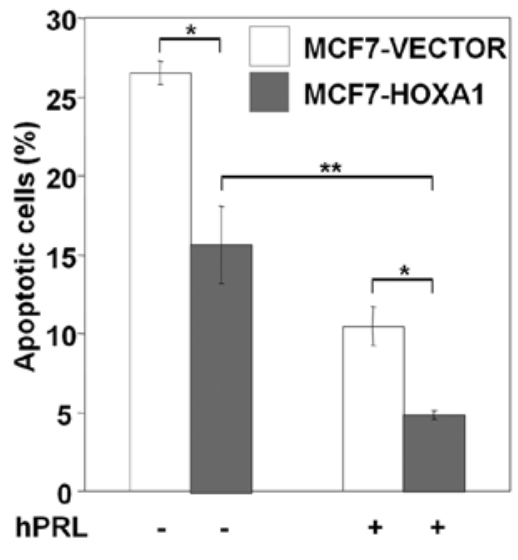

Fold decrease by hPRL: 1.72 .2

Figure 4. Forced expression of HOXA1 enhanced cell proliferation and survival in response to PRL treatment in human mammary carcinoma cells. (A) Total cell number assays. Cells were grown in 6-well plates in monolayers either in complete RPMI medium containing $10 \%$ FBS (serum) or in serum-free medium containing no FBS (serum-free) in the presence (+) or absence (-) of $2 \mu \mathrm{g} / \mathrm{ml}$ of hPRL for 3 days. The total cell number was quantified with a haemocytometer. (B) S-phase entry. Cells were grown in complete medium followed by serum starvation in serum-free medium for $24 \mathrm{~h}$ with (+) or without (-) $2 \mu \mathrm{g} / \mathrm{ml}$ of $\mathrm{hPRL}$. Cells were then labelled with bromodeoxyuridine (BrdU) and the percentage of BrdU-positive cell nuclei relative to the total number of cell nuclei was determined. (C) Apoptosis. Cells were grown as in (B), and then fixed and stained by Hoechst 33258 dye for the assessment of serum deprivation-induced apoptosis. The percentages of apoptotic cells with apoptotic nuclei out of the total number of cells are presented. All the results are presented as means \pm SE of three independent experiments each in triplicate. The effect of hPRL treatments is shown as fold increase in comparison with the untreated control. ${ }^{*} \mathrm{P}<0.05$; ${ }^{* *} \mathrm{P}<0.01 ;{ }^{* * *} \mathrm{P}<0.001$.

In media with 5\% FBS, hPRL increased both MCF7-VECTOR cell colony formation (2.4-fold) and MCF7-HOXA1 cell colony formation (3.0-fold). Therefore, HOXA1 enhanced hPRL-stimulated soft agar colony formation of MCF-7 cells.

To further investigate the involvement of PRLR in HOXA1-mediated oncogenicity in mammary carcinoma cells, we examined the effect of $\Delta 1-9-$ G129R-hPRL, an hPRL variant, on HOXA1-mediated anchorage-independent growth. $\Delta 1-9-G 129 R-h P R L$ has been demonstrated to act as a pure antagonist to the human and mouse PRLR in vitro (48) and to the mouse PRLR in vivo (59). As shown in Fig. 5B, application of the antagonist $\Delta 1-9-\mathrm{G} 129 \mathrm{R}-\mathrm{hPRL}$ at $10 \mu \mathrm{g} / \mathrm{ml}$ significantly reduced the number of colonies formed by MCF7-HOXA1 cells (1.28-fold) but did not affect the colony formation ability of the control cell line, MCF7-VECTOR. Compared with the control cell line, forced expression of HOXA1 in MCF-7 cells still resulted in a significant increase (2.1-fold) in colony formation in soft agar following treatment with the PRLR antagonist. Therefore, PRLR antagonism reduces the oncogenicity of HOXA1 in mammary carcinoma cells.

\section{Discussion}

In the present study, we have demonstrated that the transcription factor, HOXA1, upregulates PRLR-LF gene transcription and subsequent protein expression in mammary carcinoma MCF-7 cells. As a result, HOXA1 enhances hPRL-stimulated activation of both STAT5A/B and MAPK. Upon hPRL treatment, HOXA1-overexpressing MCF-7 cells not only exhibit elevated cell proliferation and decreased apoptotic cell death, but also increased anchorage-independent growth, which is partially inhibited with a PRLR antagonist. Therefore, one 


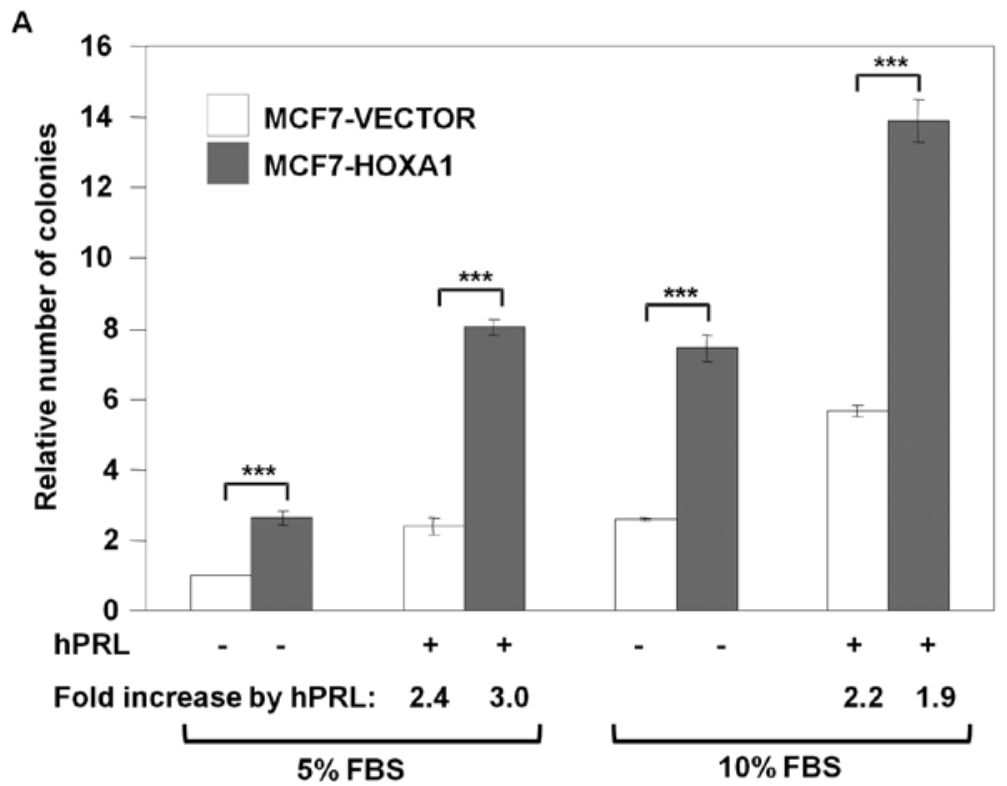

B

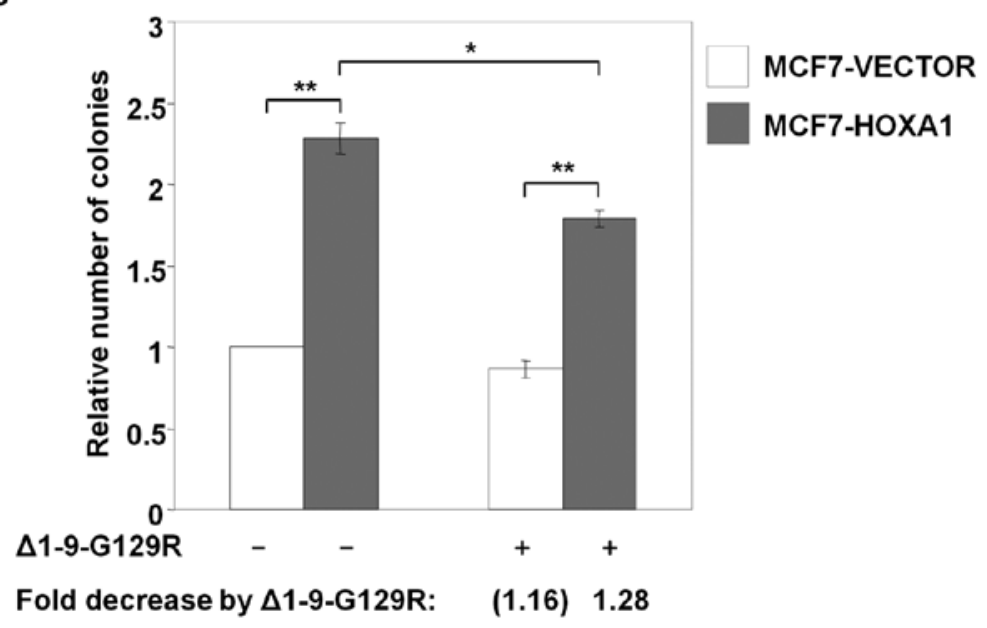

Figure 5. Forced expression of HOXA1 enhanced PRL-induced oncogenicity partially via PRLR signalling in human mammary carcinoma cells. Soft agar colony formation assays were carried out by seeding cells in $0.35 \%$ agarose in full RPMI-1640 medium containing (A) 5 or $10 \%$ FBS in 6-well plates in triplicate supplemented with or without $2 \mu \mathrm{g} / \mathrm{ml} \mathrm{hPRL}$, or (B) containing 10\% FBS supplemented with or without $10 \mu \mathrm{g} / \mathrm{ml}$ of the hPRL antagonist, $\Delta 1-9-\mathrm{G} 129 \mathrm{R}-\mathrm{hPRL}$. Colonies formed after incubation for 14 days were counted. Data are presented as means $\pm \mathrm{SE}$ of three independent experiments relative to the number of colonies formed by MCF7-VECTOR cells in (A) 5\% FBS without hPRL treatment or in (B) 10\% FBS without the hPRLR antagonist. The effect of hPRL (or $\triangle 1-9$-G129RhPRL) treatment is shown as fold increase (or decrease) in comparison with the untreated control. Values in parenthesis indicate insignificant changes. "P<0.05; ${ }^{* * *} \mathrm{P}<0.01 ;{ }^{* * *} \mathrm{P}<0.001$.

mechanism by which HOXA1 stimulates the oncogenicity of human mammary carcinoma cells is through modulation of PRLR-LF expression resulting in increased activation of downstream effectors following binding of PRLR ligands such as hPRL.

Forced expression of HOXA1 in immortalized human mammary epithelial cells has been previously demonstrated to increase total cell number, primarily by the promotion of cell survival as a result of transcriptional upregulation of BCL-2 (10). The p44/42 MAP kinase pathway was identified as one major effector of HOXA1-mediated oncogenicity and oncogenic transformation of human mammary epithelial cells in a microarray analysis to identify the downstream targets of HOXA1 (19). PRLR was also one of the HOXA1-targeted molecules indentified in the same microarray analysis (19). Although it has been conclusively demonstrated that absence of PRLR signalling results in an increased latency of tumour appearance in recognised mouse models of mammary tumorigenesis $(60,61)$, the role of PRL/PRLR signalling in human tumorigenesis is still not well defined (21). We therefore investigated the involvement of PRLR signalling, initiated via hPRL stimulation, in HOXA1-induced oncogenicity in human mammary carcinoma cells.

The PRLR is expressed in virtually all tissues, including the breast (32). PRL is primarily produced by pituitary lactotroph cells, and delivered to its numerous target tissues via the blood circulation. There is clear evidence that the mammary gland as well as several other human tissues also express PRL (22). Early studies indicate that almost all (98\%) of human breast cancers express PRL and PRLR $(25,62,63)$. A recent study indicated that the actual level of PRLR expression in most breast cancers is lower than initially expected (64), but 
even very low levels of PRLR expression were sufficient to mediate PRL responsiveness in breast cancer cell lines such as AU565 and MCF-7 (64). There is now strong epidemiological evidence supporting increased circulating PRL as a risk factor for breast cancer $(31,65)$. Studies investigating survival in breast cancer patients suggest that high pre-treatment levels of PRL are associated with treatment failure, earlier recurrence, and worse overall survival (66). Also, tumoral hPRL expression in breast cancer is associated with worse relapse-free survival and overall survival (67). One possible mechanism by which PRLR contributes to mammary tumorigenesis is through generating an autocrine-paracrine loop stimulated by local production of PRL (21), which uses JAK2/STAT5/cyclin D1 in mediating the proliferative signal induced by PRL $(34,68)$. In the present study, PRL treatment was demonstrated to rapidly activate STAT5A/B in mammary carcinoma cells. This activation was increased by HOXA1. In fact, STAT5A/B has been shown to promote malignant transformation, increase tumour growth in early stages of breast cancer, and maintain differentiation of mammary epithelium in established breast cancer $(69,70)$.

The p44/42 MAP kinases are key signal transducers involved in cell proliferation and survival (71-73). Activation of the MAP kinase pathway has been demonstrated to be a frequent event in tumorigenesis $(74,75)$. Elevated levels of phosphorylated p44/42 MAP kinases are observed in 25-50\% of breast tumours (76). Our previous study demonstrated that p44/42 MAPK signalling pathway played a key role in HOXA1-stimulated oncogenicity in mammary carcinoma cells and HOXA1-mediated oncogenicity was p44/42 MAP kinase-dependent (19). The MAPK pathway is also a very important cascade activated by the PRLR $(30,31)$. It involves the Shc/Grb2/Sos/Ras/Raf intermediaries upstream to MAPK kinase and p44/42 MAP kinases (30). Concordantly, we have demonstrated here that HOXA1 increases the PRL-induced p44/42 MAP kinase phosphorylation as well as downstream Elk-1-mediated transcription in mammary carcinoma cells.

Evasion of apoptosis has been observed to be critical for the development and sustained growth of cancerous cells (77). BCL-2 family members are important regulators of the mitochondrial pathway of apoptosis. Dysregulation of antiapoptotic BCL-2 protein often leads to increased survival of cancer cells (78). The HOXA1-induced increase in anchorage-independent proliferation in immortalized human mammary epithelial cells was primarily achieved by the promotion of cell survival mediated by the transcriptional upregulation of BCL-2 (10). HOXA1-stimulated upregulation of BCL-2 was previously demonstrated to be p44/42 MAP kinase-dependent (19). In the present study, we have demonstrated that forced expression of HOXA1 increases cell proliferation and survival in response to hPRL treatment in human mammary carcinoma cells. Activated STAT3 and STAT5 pathways have also been reported to increase BCL-2 expression levels $(79,80)$. Thus, HOXA1mediated increase in PRL-stimulated cell proliferation and survival could result from the upregulation of BCL-2 through the activation of p44/42 MAP kinase and STAT5A/B-mediated transcription.

Anchorage-independent growth of cancer cells in soft agar is a hallmark of oncogenic transformation and results from increased proliferation and altered cell-cell and cell-matrix interactions (77). HOXA1 expression was previously reported to significantly increase the growth ability of mammary carcinoma cells in soft agar (10), which was largely dependent on p44/42 MAP kinase (19). Previous studies demonstrated that PRL increased the colony forming efficiency of breast cancer cells in soft agar by up to $25 \%$ (81), and the PRLR antagonist $\Delta 1-9-G 129 R-h P R L$ reduced the PRL-induced colony-forming ability (82). In the present study, we have demonstrated that 11-9-G129R-hPRL attenuates HOXA1 mediated colony formation in soft agar by mammary carcinoma cells, indicating HOXA1 can partially exert its oncogenicity via PRLR activation. Since bovine PRL (present in FBS) is a very poor activator of the human PRLR, it is likely that the antagonist inhibited PRLR ligands secreted by MCF-7 cells (i.e. autocrine ligands) as MCF-7 cells have endogenous PRL expression, albeit at very low levels (Fig. 1A). $\Delta 1-9-G 129 R-h P R L$ is a 'pure' PRLR antagonist and devoid of any agonist activity $(48,59)$. It has been shown to reduce the PRL-induced activation of STAT3 and STAT5 in T47D human breast cancer cells (48) and decrease apoptosis in prostate cancer cell lines by antagonising autocrine PRL-mediated JAK2/STAT5A/B signalling (83). Therefore, PRLR could modulate HOXA1induced oncogenicity in human mammary carcinoma cells by directly enhancing the activation of STAT5A/B as a result of upregulation of PRLR by HOXA1.

In conclusion, we have demonstrated that HOXA1 upregulates PRLR-LF mRNA and protein expression in mammary carcinoma MCF-7 cells and that PRLR partially mediates HOXA1-induced oncogenicity by virtue of enhancing PRL/PRLR-induced activation of STAT5A/B and MAPK signalling pathways, promoting cell proliferation and survival, and increasing anchorage-independent growth of mammary carcinoma cells.

\section{Acknowledgements}

We thank Ora Emslie for critical reading of the manuscript. This study was supported by the Kelliher Charitable Trust and the Liggins Institute Trust.

\section{References}

1. Gray S, Pandha HS, Michael A, Middleton G and Morgan R: HOX genes in pancreatic development and cancer. JOP 12: 216-219, 2011.

2. Shah N and Sukumar S: The Hox genes and their roles in oncogenesis. Nat Rev Cancer 10: 361-371, 2010.

3. Morgan R, Pirard PM, Shears L, Sohal J, Pettengell R and Pandha HS: Antagonism of HOX/PBX dimer formation blocks the in vivo proliferation of melanoma. Cancer Res 67: 5806-5813, 2007.

4. Daniels TR, Neacato II, Rodriguez JA, Pandha HS, Morgan R and Penichet ML: Disruption of HOX activity leads to cell death that can be enhanced by the interference of iron uptake in malignant B cells. Leukemia 24: 1555-1565, 2010.

5. Shears L, Plowright L, Harrington K, Pandha HS and Morgan R: Disrupting the interaction between HOX and PBX causes necrotic and apoptotic cell death in the renal cancer lines CaKi-2 and 769-P. J Urol 180: 2196-2201, 2008.

6. Plowright L, Harrington KJ, Pandha HS and Morgan R: HOX transcription factors are potential therapeutic targets in non-small-cell lung cancer (targeting HOX genes in lung cancer). Br J Cancer 100: 470-475, 2009.

7. Aulisa L, Forraz N, McGuckin C and Hartgerink JD: Inhibition of cancer cell proliferation by designed peptide amphiphiles. Acta Biomater 5: 842-853, 2009. 
8. Morgan R, Plowright L, Harrington KJ, Michael A and Pandha HS: Targeting HOX and PBX transcription factors in ovarian cancer. BMC Cancer 10: 89, 2010.

9. Jung C, Kim RS, Lee SJ, Wang C and Jeng MH: HOXB13 homeodomain protein suppresses the growth of prostate cancer cells by the negative regulation of T-cell factor 4 . Cancer Res 64: 3046-3051, 2004.

10. Zhang X, Zhu T, Chen Y, Mertani HC, Lee KO and Lobie PE: Human growth hormone-regulated HOXA1 is a human mammary epithelial oncogene. J Biol Chem 278: 7580-7590, 2003.

11. Friedmann Y, Daniel CA, Strickland P and Daniel CW: Hox genes in normal and neoplastic mouse mammary gland. Cancer Res 54: 5981-5985, 1994.

12. Raman V, Martensen SA, Reisman D, et al: Compromised HOXA5 function can limit p53 expression in human breast tumours. Nature 405: 974-978, 2000.

13. Wu X, Chen H, Parker B, et al: HOXB7, a homeodomain protein, is overexpressed in breast cancer and confers epithelialmesenchymal transition. Cancer Res 66: 9527-9534, 2006.

14. Makiyama K, Hamada J, Takada M, et al: Aberrant expression of HOX genes in human invasive breast carcinoma. Oncol Rep 13: 673-679, 2005.

15. Lumsden A and Krumlauf R: Patterning the vertebrate neuraxis. Science 274: 1109-1115, 1996.

16. Chariot A, Moreau L, Senterre G, Sobel ME and Castronovo V: Retinoic acid induces three newly cloned HOXA1 transcripts in MCF7 breast cancer cells. Biochem Biophys Res Commun 215: 713-720, 1995

17. Maulbecker CC and Gruss P: The oncogenic potential of deregulated homeobox genes. Cell Growth Differ 4: 431-441, 1993.

18. Chariot A and Castronovo V: Detection of HOXA1 expression in human breast cancer. Biochem Biophys Res Commun 222: 292-297, 1996.

19. Mohankumar KM, Xu XQ, Zhu T, et al: HOXA1-stimulated oncogenicity is mediated by selective upregulation of components of the p44/42 MAP kinase pathway in human mammary carcinoma cells. Oncogene 26: 3998-4008, 2007.

20. Jacobson EM, Hugo ER, Borcherding DC and Ben-Jonathan $\mathrm{N}$ : Prolactin in breast and prostate cancer: molecular and genetic perspectives. Discov Med 11: 315-324, 2011.

21. Fernandez I, Touraine P and Goffin V: Prolactin and human tumourogenesis. J Neuroendocrinol 22: 771-777, 2010.

22. Ben-Jonathan N, Mershon JL, Allen DL and Steinmetz RW: Extrapituitary prolactin: distribution, regulation, functions, and clinical aspects. Endocr Rev 17: 639-669, 1996.

23. Zinger M, McFarland M and Ben-Jonathan N: Prolactin expression and secretion by human breast glandular and adipose tissue explants. J Clin Endocrinol Metab 88: 689-696, 2003.

24. Bhatavdekar JM, Patel DD, Shah NG, et al: Prolactin as a local growth promoter in patients with breast cancer: GCRI experience. Eur J Surg Oncol 26: 540-547, 2000.

25. Reynolds C, Montone KT, Powell CM, Tomaszewski JE and Clevenger CV: Expression of prolactin and its receptor in human breast carcinoma. Endocrinology 138: 5555-5560, 1997.

26. Touraine P, Martini JF, Zafrani B, et al: Increased expression of prolactin receptor gene assessed by quantitative polymerase chain reaction in human breast tumors versus normal breast tissues. J Clin Endocrinol Metab 83: 667-674, 1998.

27. Tran-Thanh D, Arneson NC, Pintilie M, et al: Amplification of the prolactin receptor gene in mammary lobular neoplasia. Breast Cancer Res Treat 128: 31-40, 2011.

28. Bogorad RL, Courtillot C, Mestayer C, et al: Identification of a gain-of-function mutation of the prolactin receptor in women with benign breast tumors. Proc Natl Acad Sci USA 105: 14533-14538, 2008

29. Bouilly J, Sonigo C, Auffret J, Gibori G and Binart N: Prolactin signaling mechanisms in ovary. Mol Cell Endocrinol 356: 80-87, 2012.

30. Goffin V, Bernichtein S, Touraine P and Kelly PA: Development and potential clinical uses of human prolactin receptor antagonists. Endocr Rev 26: 400-422, 2005.

31. Clevenger CV, Furth PA, Hankinson SE and Schuler LA: The role of prolactin in mammary carcinoma. Endocr Rev 24: 1-27, 2003.

32. Bole-Feysot C, Goffin V, Edery M, Binart N and Kelly PA: Prolactin (PRL) and its receptor: actions, signal transduction pathways and phenotypes observed in PRL receptor knockout mice. Endocr Rev 19: 225-268, 1998.
33. Kirken RA, Malabarba MG, Xu J, et al: Prolactin stimulates serine/tyrosine phosphorylation and formation of heterocomplexes of multiple Stat5 isoforms in Nb2 lymphocytes. J Biol Chem 272: 14098-14103, 1997.

34. Brockman JL, Schroeder MD and Schuler LA: PRL activates the cyclin D1 promoter via the Jak2/Stat pathway. Mol Endocrinol 16: 774-784, 2002.

35. Matsumoto A, Masuhara M, Mitsui K, et al: CIS, a cytokine inducible $\mathrm{SH} 2$ protein, is a target of the JAK-STAT5 pathway and modulates STAT5 activation. Blood 89: 3148-3154, 1997.

36. Zhu T, Starling-Emerald B, Zhang X, et al: Oncogenic transformation of human mammary epithelial cells by autocrine human growth hormone. Cancer Res 65: 317-324, 2005.

37. Liu DX and Lobie PE: Transcriptional activation of $\mathrm{p} 53$ by Pitx1. Cell Death Differ 14: 1893-1907, 2007.

38. Ma FY, Anderson GM, Gunn TD, Goffin V, Grattan DR and Bunn SJ: Prolactin specifically activates signal transducer and activator of transcription $5 \mathrm{~b}$ in neuroendocrine dopaminergic neurons. Endocrinology 146: 5112-5119, 2005.

39. Kang J, Qian PX, Pandey V, et al: Artemin is estrogen regulated and mediates antiestrogen resistance in mammary carcinoma. Oncogene 29: 3228-3240, 2010.

40. Wood TJ, Sliva D, Lobie PE, et al: Mediation of growth hormone-dependent transcriptional activation by mammary gland factor/Stat 5. J Biol Chem 270: 9448-9453, 1995.

41. Wood TJ, Sliva D, Lobie PE, et al: Specificity of transcription enhancement via the STAT responsive element in the serine protease inhibitor 2.1 promoter. Mol Cell Endocrinol 130: 69-81, 1997.

42. Clarkson RW, Shang CA, Levitt LK, Howard T and Waters MJ: Ternary complex factors Elk-1 and Sap-1a mediate growth hormone-induced transcription of egr-1 (early growth response factor-1) in 3T3-F442A preadipocytes. Mol Endocrinol 13: 619-631, 1999.

43. Gille H, Kortenjann M, Thomae O, et al: ERK phosphorylation potentiates Elk-1-mediated ternary complex formation and transactivation. EMBO J 14: 951-962, 1995.

44. Janknecht R and Hunter T: Convergence of MAP kinase pathways on the ternary complex factor Sap-1a. EMBO J 16: $1620-1627,1997$

45. Rahnama F, Shafiei F, Gluckman PD, Mitchell MD and Lobie PE: Epigenetic regulation of human trophoblastic cell migration and invasion. Endocrinology 147: 5275-5283, 2006.

46. Kaulsay KK, Zhu T, Bennett W, Lee KO and Lobie PE: The effects of autocrine human growth hormone $(\mathrm{hGH})$ on human mammary carcinoma cell behavior are mediated via the hGH receptor. Endocrinology 142: 767-777, 2001.

47. Del BG, Darzynkiewicz Z, Degraef C, Mosselmans R, Fokan D and Galand P: Comparison of methods based on annexin-V binding, DNA content or TUNEL for evaluating cell death in HL-60 and adherent MCF-7 cells. Cell Prolif 32: 25-37, 1999.

48. Bernichtein S, Kayser C, Dillner K, et al: Development of pure prolactin receptor antagonists. J Biol Chem 278: 35988-35999, 2003.

49. Fields K, Kulig E and Lloyd RV: Detection of prolactin messenger RNA in mammary and other normal and neoplastic tissues by polymerase chain reaction. Lab Invest 68: 354-360, 1993.

50. Ginsburg E and Vonderhaar BK: Prolactin synthesis and secretion by human breast cancer cells. Cancer Res 55 : 2591-2595, 1995.

51. Nevalainen MT, Valve EM, Ingleton PM, Nurmi M, Martikainen PM and Harkonen PL: Prolactin and prolactin receptors are expressed and functioning in human prostate. J Clin Invest 99: 618-627, 1997.

52. Clevenger CV, Chang WP, Ngo W, Pasha TL, Montone KT and Tomaszewski JE: Expression of prolactin and prolactin receptor in human breast carcinoma. Evidence for an autocrine/ paracrine loop. Am J Pathol 146: 695-705, 1995.

53. Meng J, Tsai-Morris CH and Dufau ML: Human prolactin receptor variants in breast cancer: low ratio of short forms to the long-form human prolactin receptor associated with mammary carcinoma. Cancer Res 64: 5677-5682, 2004.

54. Li Y, Clevenger CV, Minkovsky N, et al: Stabilization of prolactin receptor in breast cancer cells. Oncogene 25: 1896-1902, 2006.

55. Benbassat C, Shoba LN, Newman M, Adamo ML, Frank SJ and Lowe WL Jr: Growth hormone-mediated regulation of insulin-like growth factor I promoter activity in C6 glioma cells. Endocrinology 140: 3073-3081, 1999. 
56. Galsgaard ED, Gouilleux F, Groner B, Serup P, Nielsen JH and Billestrup N: Identification of a growth hormone-responsive STAT5-binding element in the rat insulin 1 gene. Mol Endocrinol 10: 652-660, 1996.

57. Bergad PL, Shih HM, Towle HC, Schwarzenberg SJ and Berry SA: Growth hormone induction of hepatic serine protease inhibitor 2.1 transcription is mediated by a Stat5-related factor binding synergistically to two gamma-activated sites. J Biol Chem 270: 24903-24910, 1995.

58. Freedman VH and Shin SI: Cellular tumorigenicity in nude mice: correlation with cell growth in semi-solid medium. Cell 3: 355-359, 1974.

59. Rouet V, Bogorad RL, Kayser C, et al: Local prolactin is a target to prevent expansion of basal/stem cells in prostate tumors. Proc Natl Acad Sci USA 107: 15199-15204, 2010.

60. Vomachka AJ, Pratt SL, Lockefeer JA and Horseman ND Prolactin gene-disruption arrests mammary gland development and retards T-antigen-induced tumor growth. Oncogene 19: 1077-1084, 2000.

61. Oakes SR, Robertson FG, Kench JG, et al: Loss of mammary epithelial prolactin receptor delays tumor formation by reducing cell proliferation in low-grade preinvasive lesions. Oncogene 26: 543-553, 2007.

62. Ormandy CJ, Hall RE, Manning DL, et al: Coexpression and cross-regulation of the prolactin receptor and sex steroid hormone receptors in breast cancer. J Clin Endocrinol Metab 82: 3692-3699, 1997.

63. Mertani HC, Garcia-Caballero T, Lambert A, et al: Cellular expression of growth hormone and prolactin receptors in human breast disorders. Int J Cancer 79: 202-211, 1998.

64. Galsgaard ED, Rasmussen BB, Folkesson CG, et al: Re-evaluation of the prolactin receptor expression in human breast cancer. J Endocrinol 201: 115-128, 2009.

65. Bernichtein S, Touraine P and Goffin V: New concepts in prolactin biology. J Endocrinol 206: 1-11, 2010.

66. Tworoger SS and Hankinson SE: Prolactin and breast cancer etiology: an epidemiologic perspective. J Mammary Gland Biol Neoplasia 13: 41-53, 2008.

67. Wu ZS, Yang K, Wan Y, et al: Tumor expression of human growth hormone and human prolactin predict a worse survival outcome in patients with mammary or endometrial carcinoma. J Clin Endocrinol Metab 96: E1619-E1629, 2011.

68. Schroeder MD, Symowicz J and Schuler LA: PRL modulates cell cycle regulators in mammary tumor epithelial cells. Mol Endocrinol 16: 45-57, 2002.
69. Tan SH and Nevalainen MT: Signal transducer and activator of transcription $5 \mathrm{~A} / \mathrm{B}$ in prostate and breast cancers. Endocr Relat Cancer 15: 367-390, 2008.

70. Wagner KU and Rui H: Jak2/Stat5 signaling in mammogenesis, breast cancer initiation and progression. J Mammary Gland Biol Neoplasia 13: 93-103, 2008.

71. Su B and Karin M: Mitogen-activated protein kinase cascades and regulation of gene expression. Curr Opin Immunol 8: 402-411, 1996.

72. van BT, Hawes BE, Luttrell DK, et al: Receptor-tyrosinekinase- and $\mathrm{G} \beta \gamma$-mediated MAP kinase activation by a common signalling pathway. Nature 376: 781-784, 1995.

73. Kim EK and Choi EJ: Pathological roles of MAPK signaling pathways in human diseases. Biochim Biophys Acta 1802: 396-405, 2010.

74. Mansour SJ, Matten WT, Hermann AS, et al: Transformation of mammalian cells by constitutively active MAP kinase kinase. Science 265: 966-970, 1994.

75. Grant S: Cotargeting survival signaling pathways in cancer. J Clin Invest 118: 3003-3006, 2008.

76. Salh B, Marotta A, Matthewson C, et al: Investigation of the Mek-MAP kinase-Rsk pathway in human breast cancer. Anticancer Res 19: 731-740, 1999.

77. Hanahan D and Weinberg RA: Hallmarks of cancer: the next generation. Cell 144: 646-674, 2011.

78. Llambi F and Green DR: Apoptosis and oncogenesis: give and take in the BCL-2 family. Curr Opin Genet Dev 21: 12-20, 2011.

79. Hattori R, Maulik N, Otani H, et al: Role of STAT3 in ischemic preconditioning. J Mol Cell Cardiol 33: 1929-1936, 2001.

80. Lord JD, McIntosh BC, Greenberg PD and Nelson BH: The IL-2 receptor promotes lymphocyte proliferation and induction of the c-myc, bcl-2, and bcl-x genes through the trans-activation domain of Stat5. J Immunol 164: 2533-2541, 2000.

81. Manni A, Wright C, Davis G, Glenn J, Joehl R and Feil P: Promotion by prolactin of the growth of human breast neoplasms cultured in vitro in the soft agar clonogenic assay. Cancer Res 46: 1669-1672, 1986.

82. Howell SJ, Anderson E, Hunter T, Farnie G and Clarke RB: Prolactin receptor antagonism reduces the clonogenic capacity of breast cancer cells and potentiates doxorubicin and paclitaxel cytotoxicity. Breast Cancer Res 10: R68, 2008.

83. Dagvadorj A, Collins S, Jomain JB, et al: Autocrine prolactin promotes prostate cancer cell growth via Janus kinase-2-signal transducer and activator of transcription-5a/b signaling pathway. Endocrinology 148: 3089-3101, 2007. 